\title{
Global Food Safety: Perspectives, Challenges, and Plans
}

\author{
Kimberly J. Harris*
}

Department of Hospitality Management, B4112 University Center, 288 Champions Way, Dedman School of Hospitality, College of Business, Florida State University, Tallahassee, FL, USA

*Corresponding author: Kimberly J. Harris, Professor, Bessie Morgan Marshall Professor of Hospitality Management, B4112 University Center, 288 Champions Way, Dedman School of Hospitality, College of Business, Florida State University, Tallahassee, FL 32306-2541, USA, Tel: 011-850-644-8246; E-mail: kharris@fsu.edu

\begin{abstract}
The issue of supplying safe food on a global scale is a complicated task. With the advances in expectations from consumers to have a variety of food products from around the world available in their immediate area, the focus on how to meet this demand and do so safely challenges not only the delivery systems used for food transport, but the knowledge base of food safety experts and governmental agencies around the globe. The purpose of this article is to investigate research on the global initiatives to provide safe food through the chain of delivery, beginning with growers, distributors, transporters, retailers and non-profit organizations. Additionally, presenting the food safety inspection process and issues with the systems used in a variety of countries, are included.
\end{abstract}

Keywords: Food safety; Sanitation; Foodborne illness outbreaks; Food safety inspection systems; Food control; Food safety regulations
Received Date: April 05, 2016

Accepted Date: July 18, 2016

Published Date: July 25, 2016

Citation: Harris, K.J. Global Food Safety: Perspectives, Challenges, and Plans. (2016) Int J Food Nutr Sci 3(2): 315- 319.

DOI: $10.15436 / 2377-0619.16 .854$

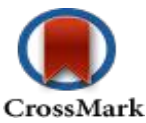

\section{Introduction}

Food safety is on the forefront of global tourism concerns. Reports from the World Health Organization (WHO) state that food safety is a concern for countries considered to be third world with few advances in food protection as well as those with sophisticated food management systems ${ }^{[1]}$. The lack of internationally accepted guidelines and a consistently proven food handling monitoring system requiring suppliers, transporters, distributors, growers, and handlers to food to follow are just a few of the issues challenging the quest to deliver safe food to consumers ${ }^{[2,3]}$.

For high tourism cities throughout North America, Europe, Asia, and African continents, food safety organizations report concerns of food safety. This global concern merits the development of a strategy that would apply internationally to the hospitality industry and by implemented by food handlers worldwide. This strategy, once in place and tested for usability, would yield a marketing program to the public communicating that 1) safe handling of food was of top priority to tourism entities, 2) food products are monitored and safe for consumption, and 3) liability would lie with every entity that handled the product and stiff penalties would result should a foodborne illness occur ${ }^{[4]}$. The precautions to travelers by such entities as the National Sanitation Foundation (NSF), Food and Drug Administration (FDA), Centers for Disease Control (CDC), European Union(EU), and British Retail Consortium (BRC) for Food, are in support of such a strategy and are synchronously committed to providing the world with safe products. According to leaders of said organizations, all must band together to protect the public ${ }^{[5-8]}$.

The Global Standard for Food Safety (GSFS) is one such program aimed at determining the threats, identifying the barriers, and offering solutions to providing safe food in the retail and private sector ${ }^{[5,9]}$. Additional programs with the same goals include the Food Safety Law under the China Food and Drug Administration (CFDA) in China ${ }^{[10]}$, the Food Safety Modernization Act in 
the United States ${ }^{[1]]}$, and Abu Dhabi Food Control Authority ${ }^{[4,7,8]}$. Each organization in their annual reports state that the chain of food supply and delivery to consumers is fraught with breakdowns in monitoring, inconsistent methods for inspecting food and lack attention to detail ${ }^{[2]}$. It would appear that the global strategy is supported in idea, but in reality, a difficult task to accomplish.

\section{Challenges to overcome in implementing a global safe food handling program}

Challenging scientists are methods of keeping a myriad of food requiring different handling methods and deterioration dates safe through the chain of delivery. Challenging processors are methods of production that treat each food independently according to its unique requirements, challenging retailers are methods of how to receive, store, and deliver foods from all over the world in timely and safe manner, and finally, challenging the consumers are decision-making skills that pose the need for food safety education, handling food safety in the home, reducing their risk of selecting unsafe from a variety of resources, and knowing what to do when they encounter foods that may pose a threat. Finances and budgetary constraints pose latch key hurdles to all entities on a global scale, to funding the necessary research and systems integration required to keep food flowing through the chain of distribution. Finding ways to eliminate stop-gaps due to poor boarder inspection control, lack of standard operating procedures, and at the most basic procedural level, inconsistent inspection forms are critical to successful global food safety ${ }^{[12,13]}$.

\section{Literature Review}

Keeping food safe is becoming more difficult to control. Due to the increased complications of food handling and monitoring as products are trading at an alarming rate between and within borders, changes to regulations are occurring in countries where food is critical in keeping the population healthy as well as a tourism trade product to which a significant contribution to their gross national product can be attributed. Food currency, or food that is used as a main import and export, requires scientists as well as knowledgeable regulatory agents to put safe food as a priority.

Trading live, organic products is different than trading such items as metals, cars, technology, or services; the product has a 'zero count shelf-life, ${ }^{\text {'[14] }}$, a term well known to food handlers, meaning that every hour the product is on a countdown to spoilage. The corporate responsibility is immense in that they must interact with stakeholders, expressing and proving concern for social and environmental concerns. Corporations involved in the food supply chain of events experience in delivering food the consumer mostly consists of internal commitment of voluntary actions as opposed to government intervention, as corporations have found governmental sanctions to be expensive, negative media to be damaging, and failure to institute protective policies to be discouraging to employee motivation and job satisfaction ${ }^{[15,16]}$. According to Powell et al $(2011)^{[17]}$, instituting a food safety culture within an organization can result in significant improvements in food handling, improve employee morale, and provide an extra layer of security to consumers if celebrated. Marketing efforts to include food safety culture commitment, internal training and awards based on performance, and engagement in professional food safety organizations are keys to improving overall food safety internally and externally to all organizations that handle food as a commodity or products processed and delivered directly to the consumer.

\section{Handling a perishable commodity: protection is paramount}

Food products have to have temperature controls, handling limitations, protections from atmospherics conditions such as light and air, and be packed such as to product the integrity of the product against infiltration in any manner. Some products are so susceptible to deterioration that immediate shipping and delivery within 24 hours or less is required. The immense chain of events that must be in concert at exactly the right time with little to no error is paramount to product the quality of not only appearance, but usability and nutritional value; therefore, timing of food movement is critical to overall food quality ${ }^{[18]}$. Food transportation, therefore, is an area of concern for distributors who have expressed the need for technology be available to improve cold storage, strategies to manage waste during transport, international agreements for landfill access for food refused or considered unwanted, and improvements to food storage for products that must be removed from transportation vehicles/equipment from one location and received by another for further transport ${ }^{[19]}$.

In several countries, the protection of food is important enough to make mishandling or adulteration of food that is targeted for consumers is a criminal offense. In China, the 2014 Work Report released by the Supreme People's Court, reported over 2,000 criminal offenses, resulting in convictions of 2,647 individuals involved in serving unsafe food ${ }^{[10]}$. The goal of such steep measures is meant to discourage those responsible for delivering food to the public from being negligent in handling consumable products and taking the actions of food safety seriously ${ }^{[20]}$. Similarly, in the United States, an unprecedented overhaul of the US Food and Drug Administration's Preventive Controls for Human Food occurred in 2011 when President Barak Obama signed a final ruling, the Food Safety Modernization Act (FSMA) to improve the handling of food for human consumption. This new rule will be fully enforced by September 2016 requires risk-based inspections for not only restaurants, but for farmers and other businesses in the food supply chain. This new ruling demands that food establishments be categorized into one of four risk-based inspection frequencies, which more stringent expectations and equally strict fines, closures, or imprisonment for non-compliance.

According to Godfray et al (2010) ${ }^{[19]}$, food security will be the future of all entities associated with food handling. Population growth in the billions will demand increased food transportation systems, increased deliveries, and an increased focus on how to feed people in areas that are difficult to access. Food producers in areas where water, land and energy will need systems developed to meet their unique needs and as the population of the more affluent in terms of wealth increase, the demands for more processed food as well as food eaten in restaurants require systems that are not reactionary, but preventive in design. A study conducted by Renzo et at (2010) ${ }^{[21]}$ of 139 food enterprises in China, suggests that food distribution companies are mainly focused on reactive measures than in futurity; giving more importance short-term solutions to food safety than long-term; however, may legislation such as the 
FSMA in the US and others presented in this paper serve as examples of the failure of reactive approaches to food safety and the overhaul of governmental policy to be more proactive in efforts to protect the public.

\section{Global leaders weigh-in on the importance of food monitoring}

As in China, the USA is taking food safety to new level by not only issuing violations with serious fines, but considering violations of food handling a crime. In the years 2008-2009, the Parnell Brothers of the Peanut Corporation of America (PCA) operated a plant in Bainbridge, Georgia, where peanut products containing Salmonella were produced and sold to the public. Both Parnell executives were sentenced to over 20 years of imprisonment that caused the deaths of nine people and sickened thousands ${ }^{[22]}$. Other examples include Great Britain, United Arab Emirates, Turkey, and Thailand. These countries are in unison that food safety is an important part of protecting human rights, acts against which are forms of food terrorism that must be punished as a criminal offense. In an article by Wongleedee (2013) ${ }^{[23]}$, results of a study that investigated the concerns from EU tourists in Thailand suggested that cultural differences in food handling when visiting countries could cause foodborne illnesses for those who are not accustomed to certain food handling and preparation techniques. The study revealed that tourist were concerned about outlets such as street vendors; small, independent restaurants; and unfamiliar, indigenous food products prepared by locals.

According to a number of other researchers ${ }^{[4,24,25]}$, a fear of food that is foreign, produced and handled by suppliers or vendors that may not be monitored. Additionally, new technologies such as the use of genetically modified organisms (GMO's) and chemicals used for fertilizers or stabilizers are of increasing concern. Baker (2003) ${ }^{[2]}$ reported that consumer information regarding the treatment and monitoring of safety measures for food is a basic human right and that risk of any degree, is unacceptable. While the decision to consume certain food is the decision of the consumer, all who receive food for consumption has the right to be protected with truthful information presented by marketers, suppliers, and food establishments who are bound by law to provide safe food.

\section{An International Food Protection Plan}

According to Yousuf et al (2015) ${ }^{[4]}$, the solution to the global awareness of food safety is to develop an international plan of action that would govern how food is produced, transported, and ultimately served to the public. Qiang $(2014)^{[20]}$ states that food safety management on a global scale is part of 'promoting the sustainable healthy development of the economy' (2014 Work Report, p.9) and conclude that failure to institute actions that protect the unsuspecting consumer is a corrupt economic crime. Qiang (2014) ${ }^{[20]}$ further suggests that crimes of food safety are similar to negligent medical conduct that endangers the innocent; therefore, laws need to be in place that clearly outline the responsibilities of entities involved in food growing, trade, and disbursement holding them accountable for contaminated goods.

Yousef et al (2015) ${ }^{[4]}$ presents a Code of Practice, supported by the Abu Dhabi Food Control Authority (ADFCA, 2016) ${ }^{[8]}$, which requires Hazard Analysis and Critical Control Point (HACCP)-based food safety management systems (FSMSs) to be a priority in serving as an example to the world as to how a global FSMS can be implemented. The Code presents frameworks extracted from the best practices of many food regulatory entities from countries. The British Retail Consortium (BRC) ${ }^{[26]}$ and the Food Safety Authority of Ireland (FSAI ${ }^{[5]}$ have impressive guidelines and further examples include the Food Code from the United States FDA, guidance from Australia's code for hospitals, and the New Zealand Food Safety Authority ${ }^{[27]}$.

\section{Barriers to implementing food safety management plans}

Despite the recommendations of global leaders and those proposing a plan of action for monitoring risk-based food products and the general handling of perishable food as a commodity, implementation of the best of plans lies culprit. The best of researched, tested, tried and true plans continue to plague food safety management programs in all countries. The myriad of people involved in the process, knowledge bases, ability to conduct thorough inspections, time to address issues, and challenges presented by those who ultimately handle the food with their different language and educational levels are just a few of the barriers to implementing the best of food safety programs ${ }^{[12]}$.

\section{What is missing: ownership of a food safety culture and micro-organism detecting tools}

Roberts et al (2008) ${ }^{[28]}$ discovered that the knowledge and behaviors of food handlers on three key monitoring activities; cross contamination, personal hygiene, and time/temperature abuse was a significant factor to poor food handling despite training and certifications earned by food handlers. According to their research, individual behaviors are not only difficult to control, but are inconsistent and unpredictable. In another study by Murphy et al. ${ }^{[13]}$, their research on the effectiveness of mandatory food safety training and certification programs had no significant effect on the occurrence of non-critical violations; however, training had a significant positive effect on the number of critical violations for large chain restaurants when compared to non-chain restaurants, suggesting that internal quality control and performance of employees that was expected by management increased a higher participation in handling food safety than did certifications or training without follow-up behavioral change expectations.

Harris et al. ${ }^{[29]}$ discovered that ethnic restaurants licensed in the state of Florida in the USA where a manager on duty is expected to be certified at the national level in food safety, were cited significantly more with having critical food safety violations as compared to chain restaurants, and suggested that language barriers, cultural food preparation techniques, and lack of proper equipment were a few reasons for failing to meet state mandated food safety expectations. The gaps between operator, inspector, and educator of food safety have yet to be addressed. Missing are tools that can be put into the hand of the food handler from farm to table that can detect harmful foodborne microorganisms before being served to the public ${ }^{[30]}$. 


\section{Conclusion, Discussion, and Limitations}

The challenge of providing safe food as the world has become ever more mobile continues to perplex. The complicated systems, or lack thereof, for handling food from farm to table are further exacerbated by the lack of consistency in food safety monitoring systems that are continually undergoing change. The traveling public as well as the indigenous populations depending and trusting in entities to provide consumable food products has no guarantee of being free of harmful food borne illness micro-organisms. Whether systemic or caused by human handling, some alterations simply cannot be managed by systems or the best of training programs; however, what is evident is the seriousness of the governmental entities responsible for protecting human rights. For some countries, failure of food providers and servers of products are held responsible for serving safe food to the public to both indigenous and non-indigenous populations. Part of the stability of a country's economy depends on the basic goal of feeding people products that do not cause harm; finding the weak link in the safe handling of all products, especially those that are risk-based, is one area that global leaders agree is a step in the right direction.

This qualitative report is limited to the entities cited and their reports. The author presents research in a collected format indicating the concern for global food safety. While it has not been determined that a program that could be implemented on a global basis has reached agreement, it is evident that food safety is a global concern and leaders of organizations tasked with monitoring food safety are discussing, if only internally, similar issues that other countries face with regard to keeping food safe for consumers. Is an international monitoring program based on agreed-to standards possible? Can it be effective? How will such a plan be implemented and what are the consequences for failure to comply? All of these questions have yet to be answered, yet what appears to be a collective agreement is that a system is in order. Suggested is continued study, open discussion at conferences and world food safety events that discuss the challenges facing food trade, safe food handling, and high quality food service to consumers. Technology is an important aspect for communication and sharing of data; therefore, it is possible that technology can assist in forming an international food safety management system as part of the fiduciary responsibility of all governments. 


\section{References}

1. World Health Organization. European Observatory on Health Systems and Policies. (2015).

2. Food and Drug Administration (FDA). (2016) Conducting risk-based inspections Annex 4.

3. Fatimah, U.Z., Boo, H.C., Sambasivan, M., et al. Foodservice hygiene factors: The consumer perspective. (2011) Int J Hosp Manag 30(1): 38-45.

4. Yousuf, M. A., Salem, S. B., Ali, A., et al. Setting the standard: The development of bespoke guides for HACCP-based food safety management systems for different sectors of the hospitality industry. (2015) Worldwide Hospitality and Tourism Themes 7(1): 3349 .

5. National Sanitation Foundation (NSF). (2016) The Public Health and Safety Organization.

6. British Retail Consortium (BRC). Food Safety: A global concern. BRC Global Standards of the British Retail Consortium. (2015).

7. Abu Dhabi Food Control Authority (ADFCA) (2010). Regulation No(6) of (2010). Food hygiene throughout the food chain.

8. Abu Dhabi Food Control Authority (ADFCA) (2016).

9. Société Générale de Surveillance (SGS). Food (2016) Agriculture and Food.

10. Balzano, J. Issues on the horizon for Chinese Food Safety Law in 2015. (2015) Forbes Asia.

11. What is new in FSMA. (2016) Food and Drug Administration (FDA).

12. Harris, K.J., DiPietro, R.B., Murphy, K.S., et al. Critical food safety violations in Florida: Relationship to location and chain verses non-chain restaurants. (2014) Int J Hosp Manag 38: 57-64.

13. Murphy, K.S., DiPietro, R.B., Kock, G., et al. Does mandatory food safety training and certification for restaurant employees improve inspection outcomes? (2011) Int J Hosp Manag 30(1): 150-156.

14. Court, A., Street, L.A., Dublin, I. Food Safety Authority of Ireland (FSAI). (2014) Validation of product shelf-life.

15. Manning, L. Corporate and consumer social responsibility in the food supply chain. (2013) British Food Journal 115(1): 9-29.

16. Maloni, M.J., Brown, M.E. Corporate social responsibility in the supply chain: An application in the food industry. (2006) J

Business Ethics 68(1): 35-52.

17. Powell, D.A., Jacob, C.J., Chapman, B.J. Enhancing food safety culture to reduce rates of foodbone illness. (2011) Food Control 22(6): 817-822.

18. Charles, D. It's Final: FDA Issues Long-Awaited Food Safety Rules. (2015) Food for Thought: The Salt.

19. Godfray, H.C., Beddington, J.R., Crute, I.R., et al. Food security: The challenge of feeding 9 billion people. (2010) Science 327(5967): 812-818.

20. Qaing, Z. 2014 Work Report of the Supreme People's Court. (2014).

21. Renzo, R., Poorya, F., Grunow, M. Quality, safety and sustainability in food distribution: A review of quantitative operations management approaches and challenges. (2010) OR Spectrum 32(4): 863-904.

22. Flynn, D. Parnell brothers finally in prison for deadly peanut butter outbreak. (2016) Food Safety News.

23. Wongleedee, K. Food safety management: Concerns from EU Tourists in Thailand. (2013) Int J Scholarly and Scientific Research \& Innovation 7(1): 94-97.

24. Kaferstein, F., Abdussalam, M. Food safety in the $21^{\text {st }}$ century. (1999) Bull World Health Organ 77(4): 347-351.

25. Baker, G.A. Food safety and fear: Factors affecting consumer response to food safety risk. (2003) Int Food Agribusiness Manag Rev 6(1): 1-11.

26. British Retail Consortium (BRC) (2016).

27. New Zealand Food Safety Authority (NZFSA) (2016).

28. Roberts, K.R., Barrett, B.B., Howells, A.D., et al. Food safety training and foodservice employees' knowledge and behavior. (2008) Food Prot Trends 28(4): 252-260.

29. Harris, K.J., Murphy, K.S., DiPietro, R.B., et al. Food safety inspections results: A comparison of ethnic-operated restaurants to non-ethnic operated restaurants. (2015) Int J Hosp Manag 46: 190-199.

30. Zeng, K., Luo, X. Food safety incidents' influence on the food industry: How food companies perceive environments and how they react strategically. (2014) China Agricultural Economic Review 6(2): 264-277.

Online ISSN: 2377-0619

Journal Title: International Journal Food and Nutritional Science

Journal Short Name: Int J Food Nutr Sci
Ommega Online Publishers

E-mail: foodscience@ommegaonline.org

Website: www.ommegaonline.org 